\title{
Analysis of infiltration, seepage processes and slope instability mechanisms during the November 2000 storm event in Tuscany
}

\author{
V. Tofani, S. Dapporto, P. Vannocci, and N. Casagli \\ Earth Sciences Department, University of Florence, Italy \\ Received: 24 October 2004 - Revised: 10 February 2005 - Accepted: 16 February 2005 - Published: 15 September 2005
}

\begin{abstract}
On the days 20-21 November 2000, a storm of exceptional intensity triggered over 50 landslides within the province of Pistoia in Tuscany (Italy). These failures are mostly of complex type, originating as rotational or translational landslides, and transforming into flows. Two of these landslides were investigated in this paper by modelling the ground water infiltration process, the pore water pressure variations, both positive and negative, and the effects of these variations on slope stability during the rainfall event. Morphometric and geotechnical analyses were carried out for both sites through a series of in-situ and laboratory tests, the results of which were used as input for the modelling process. In a first step the surface infiltration rate was simulated using a modified Chu (1978) approach for the Green and Ampt (1911) equations in case of unsteady rainfall together with a surficial water balance. A finite element seepage analysis for transient conditions was then employed to model the changes in pore water pressure during the event, using the computed infiltration rate as the ground surface boundary condition. Finally, once again using the data from the previous step as input, the limit equilibrium Morgenstern-Price (1965) slope stability method was applied to calculate the variations in the factor of safety during the event and thereby determine the most critical time of instability. In both sites this method produced a curve for the factor of safety that indicated that the most critical time for failure occurred a few hours after the peak of rainfall.
\end{abstract}

\section{Introduction}

Rainfall is considered to be the most important factor in triggering slope failure. During rainfall, water infiltrates into the ground and increases the pore water pressure, weakening the soil and facilitating landsliding. The frequency and magnitude of rainfall events, together with other fac-

Correspondence to: V. Tofani

(veronica.tofani@geo.unifi.it) tors such as lithology, morphology and land cover, influence the type of landslide. Deep-seated landslides are often triggered by moderate intensity rainfall distributed over long periods (Corominas, 2001) whereas superficial landslides such as soil slips and debris flows are triggered by short duration, intense precipitation. The response of the material involved is largely dependent on its permeability. Clayey materials, for example, are more sensitive to long, moderate intensity rainfall, as opposed to sandy soils, that tend to respond to intense short duration precipitation.

The critical quantity of precipitation defined as "the amount of rainfall from the time ("zero point") in which a sharp increase in rainfall intensity is observed and the triggering of the (first) landslide" (Aleotti, 2004) is related to slope morphology, to the mechanical and hydrological properties of the soil and to the vegetation cover. Statistical analyses of landslide characteristics and of the corresponding triggering rainfall characteristics have led to the formulation of various methods for assessing landslide-triggering rainfall thresholds (e.g. Govi and Sorzana, 1980; Crozier, 1986; Kim et al., 1991; Glade et al., 2000; Sidle and Dhakal, 2002; Ko Ko et al., 2004).

In this work the mechanism behind rainfall-triggered landslides is modelled by using combined hydrological and stability analyses. This method is based on the different terrain response according to its geological, physical, hydrogeological and mechanical characteristics. In addition, in sites where morphological and anthropogenic factors influence the superficial and subsurface fluctuations of the water flow, and hence the stability of the slope (Terlien, 1998), the method can be modified to take into account these factors. The main objective is to investigate the instability mechanisms behind rainfall-triggered landslide events, based on detailed modelling of infiltration and seepage processes during the storm of 20-21 November 2000. More specifically, the work has been conducted with the aim of increasing the understanding between the variations in positive and negative pore water pressure during the rainfall event and their effect on slope stability (Dapporto et al., 2002). 


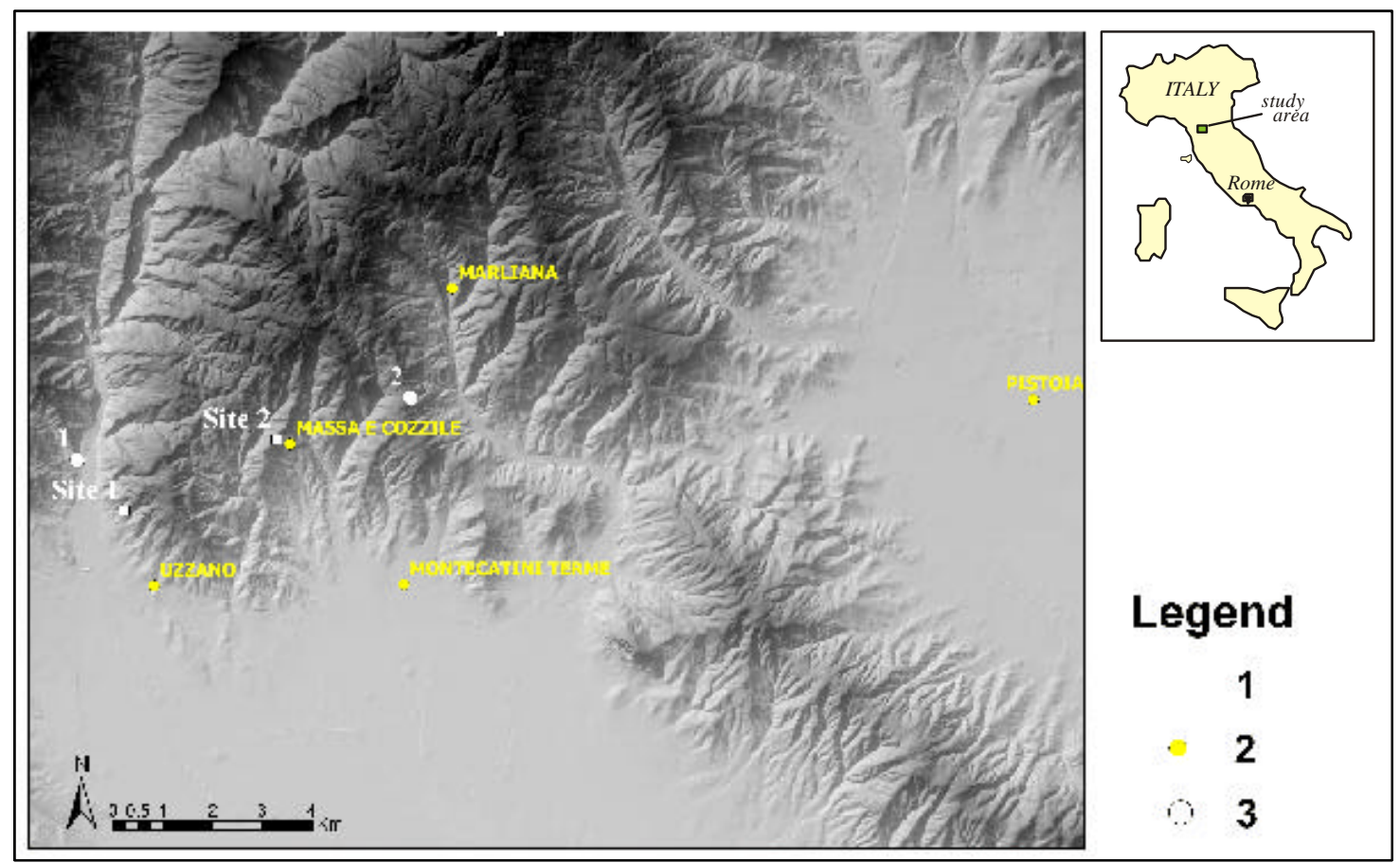

Fig. 1. Map of the study area with locations of landslides (1), nearby towns (2) and raingauge stations (3).

Table 1. Results of in-situ tests for both landslide sites.

\begin{tabular}{cccccc}
\hline Site & $\begin{array}{c}\phi^{\prime} \\
\circ\end{array}$ & $\begin{array}{c}\mathrm{c} \\
\mathrm{kPa}\end{array}$ & $\begin{array}{c}\phi^{b} \\
\circ\end{array}$ & $\begin{array}{c}u_{a}-u_{w} \\
\mathrm{kPa}\end{array}$ & $\begin{array}{c}k_{s} \\
\mathrm{~m} / \mathrm{s}\end{array}$ \\
\hline 1. Uzzano & 31.8 & 5.7 & 31.8 & 8.4 & $1.1 \mathrm{E}-6$ \\
2. Cozzile & 35.7 & 4.7 & 31.7 & 7.6 & $1.3 \mathrm{E}-6$ \\
\hline
\end{tabular}

\section{Study area and rainfall event}

The predominant rock type in the study area is a flysch formation (Macigno), composed of quartz and feldspar sandstone alternated with layers of siltstone. In the mid and upper sections of the valley, where most landslides occurred, the stratigraphy consists of a 1.5 to $2 \mathrm{~m}$ thick layer of colluvial soil overlying the bedrock.

The local topography is characterised by hills with moderate to high slope gradients and elevations ranging from $20 \mathrm{~m}$ a.s.l. to about $900 \mathrm{~m}$ a.s.l.

Annual rainfall in this area is characterised by two peaks, one in November and another in March, with a dry summer during which the mean temperature is over $22^{\circ} \mathrm{C}$. Mean annual rainfall increases with relief, ranging from $1100 \mathrm{~mm}$ in the valley bottom to about $1800 \mathrm{~mm}$ at the higher elevations.

On 20-21 November 2000, a cyclonic storm precipitated about 200 to $220 \mathrm{~mm}$ of rainfall over a period of $38-40 \mathrm{~h}$ in the Montecatini Terme area (Province of Pistoia), with a maximum intensity of $17 \mathrm{~mm} / \mathrm{h}$. The event has an estimated return period of over 100 years, determined by applying the
Gumbel distribution method to the available last 30 years rainfall record. The storm triggered over 50 landslides, involving an area of approximately $50 \mathrm{~km}^{2}$.

The two landslides selected for investigation occurred near Uzzano (site 1) and Massa e Cozzile (site 2) (Fig. 1). Both landslides are classified as complex slope movements (Hutchinson, 1988), composed of a rotational-translational failure that evolves into a flow (Fig. 2).

\section{Morphometry and characterisation of soil properties}

The topography of the two landslide sites was determined by means of a differential GPS survey of the pre- and postfailure slope profiles. The pre-failure profile was obtained by averaging the undisturbed profiles surveyed on both sides of the landslide body following the rainfall event.

Soil geotechnical parameters were determined from a series of in-situ and laboratory tests. The in-situ tests included the Borehole Shear Test (Lutenegger and Halberg, 1981; Dapporto et al., 2000), matric suction measurements with a tensiometer, and a constant head permeameter test performed with an Amoozemeter (Amoozegar, 1989) (Table 1). Grain size distribution, Atterberg limits, the phase relationship analysis and direct shear tests were conducted in the laboratory (Table 2 ).

\section{Infiltration analysis}

The infiltration rate at the surface during the rainstorm was predicted by using a modified Chu (1978) approach for the 
Table 2. Results of laboratory tests for both landslide sites.

\begin{tabular}{cccccccccccccc}
\hline Site & $\begin{array}{c}\mathrm{GF} \\
\%\end{array}$ & $\begin{array}{c}\mathrm{SF} \\
\%\end{array}$ & $\begin{array}{c}\mathrm{MF} \\
\%\end{array}$ & $\begin{array}{c}\mathrm{CF} \\
\%\end{array}$ & $\begin{array}{c}\mathrm{LL} \\
\%\end{array}$ & $\begin{array}{c}\mathrm{PL} \\
\%\end{array}$ & $\begin{array}{c}\gamma_{s a t} \\
\mathrm{kN} / \mathrm{m}^{3}\end{array}$ & $\begin{array}{c}\gamma_{d} \\
\mathrm{kN} / \mathrm{m}^{3}\end{array}$ & $\begin{array}{c}\mathrm{G}_{s} \\
-\end{array}$ & $\begin{array}{c}\mathrm{n} \\
\%\end{array}$ & $\begin{array}{c}\phi_{c v}^{\prime} \\
\circ^{\prime}\end{array}$ & $\begin{array}{c}\phi_{r}^{\prime} \\
\mathrm{c}^{\prime} \\
\mathrm{kPa}\end{array}$ \\
\hline 1. Uzzano & 12 & 43 & 35 & 10 & 26 & 16 & 19.7 & 15.8 & 2.68 & 40 & 32 & - & 0.5 \\
2. Cozzile & 1 & 85 & 13 & 1 & 29 & - & 18.9 & 14.7 & 2.67 & 44 & 35 & 18 & 0 \\
\hline
\end{tabular}

Green and Ampt (1911) equations in case of unsteady rainfall combined with a water balance at the surface.

The rainfall recorded at each of the rainfall gauges nearest the sites was discretised into a series of one-hour time steps with constant rainfall rates (Fig. 1). The infiltration rate and the start and end times of ponding conditions were computed at the end of each time step.

The data required for the infiltration analysis includes: the saturated permeability $\left(k_{s}\right)$; the volumetric water content before and after wetting $(M=\theta s-\theta i)$ and the matric suction at the wetting-front (S). The matric suction measured in the field in post-landslide conditions $(8.4 \mathrm{kPa}$ at site 1 and $7.6 \mathrm{kPa}$ at site 2) was modified to replicate the presumed initial pore water pressure in pre-landslide conditions, in which heavy antecedent rainfalls were recorded during the 20 days prior to the storm. For this reason a matric suction value of $5 \mathrm{kPa}$ was used. The volumetric water content functions, before and after wetting, were obtained from the literature for soils with a similar grain size distribution while the saturated water content $\left(\theta_{s}\right)$ was derived from the porosity (n) measured in the laboratory. In both sites, at the beginning of the storm the modelled infiltration rate is equal to the rainfall rate. Subsequently, following the onset of ponding conditions, the infiltration rate becomes equal to the maximum infiltration rate for those soil conditions or, in other words, to the infiltration capacity. The infiltration rate asymptotically tends to the value of the saturated permeability $\left(K_{S}\right)$.

\section{Seepage analysis}

Unsaturated and saturated flow within the slopes was modelled with a finite element seepage analysis using SEEP/W v.4 (Geo-Slope International Ltd.) software. The slope sections were divided into a mesh of quadrilateral elements, 1152 for Uzzano and 456 for Massa e Cozzile. The results from the infiltration analysis were used as input data for the seepage analysis by assigning the computed infiltration rate versus time function to the ground surface nodes. Zero flux conditions were assigned to the left, right and lower boundaries. An initial matric suction value of $5 \mathrm{kPa}$ was used. The hydraulic properties of the materials (characteristic and $\mathrm{k}$ curves) were estimated from the grain-size distribution of the matrix. Finally, the simulation was performed dividing the rainfall event into variable length time steps in order to replicate as closely as possible the complexity of the rainfall event.

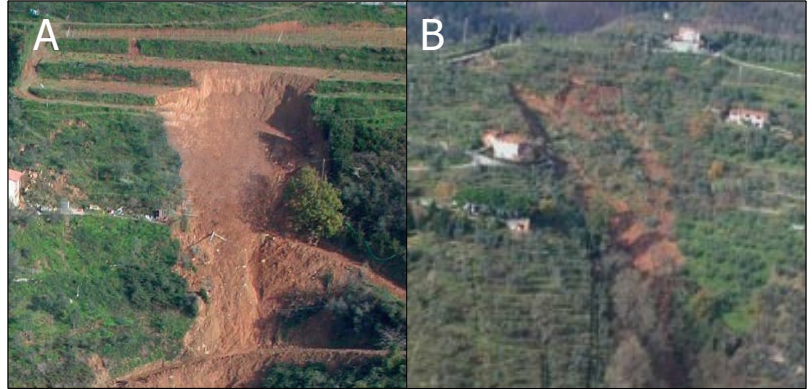

Fig. 2. Study sites. A: Site 1, Uzzano landslide, B: Site 2, Massa and Cozzile landslide.

\section{Stability analysis}

The stability analysis used the positive and negative pore water pressure distributions obtained from the seepage analysis as input at each time step. SLOPE/W v.4 (Geo-Slope International Ltd.), a software that applies limit equilibrium methods, was used to model slope stability. The MorgensternPrice (1965) method was selected to compute the factor of safety of the soil cover for each of the time steps used in the finite element seepage analysis. The failure surface was determined from the GPS measurements and was maintained constant during the entire event.

\section{Results}

The results of the combined infiltration-seepage-stability analysis indicate a similar behaviour of the Uzzano and Massa e Cozzile landslides. In both sites the factor of safety starts to decrease after the start of the rainfall (Figs. 3 and 4). This is due to the reduction of matric suction produced by the water that infiltrates into the soil. As the event progresses, the wet front descends through the soil until it reaches the impermeable bedrock, at which point a saturated layer begins to build up. During this phase in both sites the factor of safety decreases rapidly. In site 1 the factor of safety falls below 1 at step 19 (Fig. 3) while in site 2 this occurs at step 13 (Fig. 4), respectively 32 and $24 \mathrm{~h}$ after the start of the rainfall. The factor of safety then slowly begins to increase again as the pore water pressure diminishes following the end of rainfall, and stability conditions are reached four and three days after the beginning of the event, respectively. 


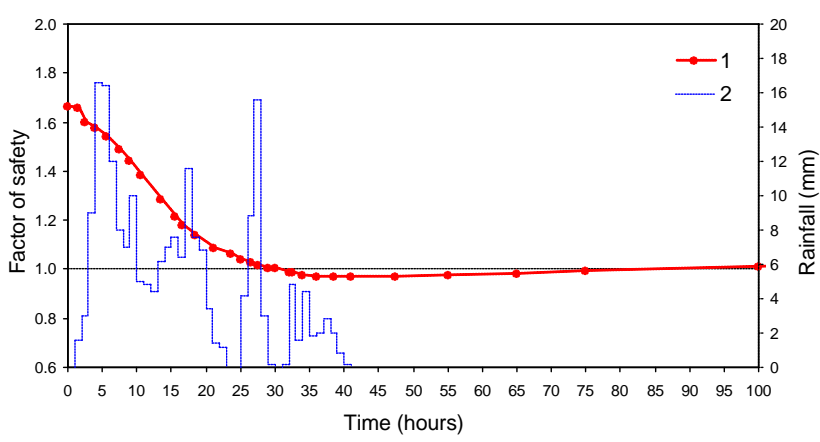

Fig. 3. Site 1. Uzzano. Trend of the computed safety factor and rainfall data during the 20-21 November 2000 event (1- factor of safety, 2- rainfall).

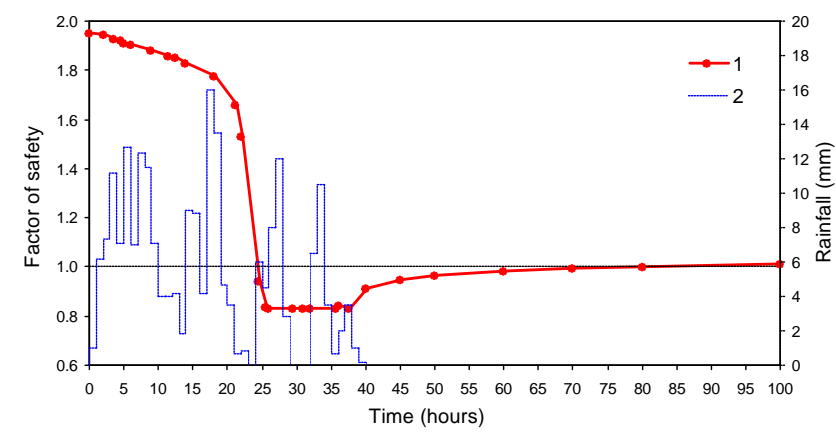

Fig. 4. Site 2. Massa e Cozzile. Trend of the computed safety factor and rainfall data during the 20-21 November 2000 event (1- factor of safety, 2- rainfall).

\section{Conclusions}

The results indicate that the simulation of saturated/unsaturated flow within the soil with a finite element seepage analysis, coupled with an infiltration model to determine the actual infiltration rate at the surface, can provide useful insight for the reconstruction of pore water pressure variations, total head and volumetric water content in response to variable intensity rainfall. The assessment of pore pressure changes at all nodes along the potential failure surface also allows an accurate slope stability analysis to be performed. The trend of the factor of safety indicates that slope failure is likely to occur a few hours after the peak of the rainfall, and that in both sites slope instability conditions persist for the following 4 days.

Edited by: L. Ferraris

Reviewed by: anonymous referees

\section{References}

Aleotti, P.: A warning system for rainfall-induced shallow failures, Engineering Geology, 73, 247-265, 2004.

Amoozegar, A.: Compact constant head permeameter for measuring saturated hydraulic conductivity of the vadose zone, Soil Science Society of American Journal, 53, 1356-1361, 1989.

Chu, S. T.: Infiltration during an unsteady rain, Water Resources Research, 14, 461-466, 1978.

Corominas, J.: Landslides and Climate, Keynote Lectures from the 8th International Symposium on Landslides, No. 4, 1-33, 2001.

Crozier, M. J.: Landslides: Causes, Consequences and Envirorment, Croom Helm, London, pp. 252, 1986.

Dapporto, S., Focardi, P., and Vannocci, P.: La parametrizzazione geotecnica di un materiale non saturo mediante prove in sito, Geologia Tecnica \& Ambientale, 3, 5-11, 2000.

Dapporto, S., Falorni, G., Tofani, V., and Vannocci, P.: Analisi delle variazioni di pressione interstiziale alla base dei movimenti franosi durante l'evento del novembre 2000 in Toscana, Conservazione dell' ambiente e rischio idrogeologico, Convegno nazionale Assisi, Italia, 11-12 dicembre 2002.

Glade, T., Crozier, M., and Smith, P.: Applying Probability Determination to Refine Landslide-triggering Rainfall Thresholds Using an Empirical "Antecedent Daily Rainfall Model”, Pure Appl. Geophys., 157, 1059-1079, 2000.

Govi, M. and Sorzana, P. F.: Landslides susceptibility as a function of critical rainfall amount in Piedmont Basins, Studia Geomorphologica Carpatho-Balcanica, 14, 43-61, 1980.

Green, W. H. and Ampt, G. A.: Studies on soil physics: 1. Flow of air and water through soils, J. Agr. Sci., 4, 1-24, 1911.

Hutchinson, J. N.: General report: Morphological and geotechnical parameters of landslides in relation to geology and hydrogeology, Proc. Fifth International Symposium on Landslides, Rotterdam, Balkema, 1, 3-36, 1988.

Kim, S. K., Hong, W. P., and Kim Y. M.: Prediction of rainfalltriggered landslides in Korea, in: Proceedings of the 6th International Symposium on Landslides, edited by: Bell, D. H., Christchurch, New Zealand, Balkema, Rotterdam, 989-994, 1991.

Ko Ko, C., Flentje, P., and Chowdhury, R.: Interpretation of probability of landsliding triggered by rainfall, Landslides, 1, 263275, 2004.

Lutenegger, A. J. and Halberg, G. R.: Borehole Shear Test in geotechnical investigation, Special Technical Publ. American Society for Testing and Materials, 740, 566-578, 1981.

Morgenstern, N. R. and Price, V. E.: The analysis of the stability of general slip surfaces, Geotechnique, 15, 79-93, 1965.

Sidle, R. C. and Dhakal, A. S.: Potential effects of environmental change on landslide hazards in forest environments, in: Environmental Change and Geomorphic Hazards in Forests, edited by: Sidle, R. C., IUFRO Research Series, CAB International Press, Oxen, UK, No. 9, pp. 123-165, 2002.

Terlien, M. T. J.: The determination of statistical and deterministic hydrological landslide-triggering thresholds. Environmental geology, 35, 2-3 August 1998. 